\title{
Anxiety and education: An examination of anxiety across a nursing program
}

\author{
Monika Wedgeworth * \\ The University of Alabama, Tuscaloosa, United States
}

Received: March 23, 2016

Accepted: May 3, 2016

Online Published: May 25, 2016

DOI: $10.5430 /$ jnep.v6n10p23

URL: http://dx.doi.org/10.5430/jnep.v6n10p23

\begin{abstract}
Nursing students report higher levels of anxiety than the overall population of college students, in part due to competition for entrance into programs, course structure, long hours of clinical experiences, and working with very sick persons. Excessive anxiety in nursing students can have negative health, academic, economic, and patient care outcomes, as well as impact future role transition into professional practice; including burnout and poor job performance. This 2013 study examined the type of anxiety that is experienced by baccalaureate nursing students, the timing, and severity of anxiety within the program of study. The results showed that a significant number of nursing students experienced state and trait anxiety at alarmingly high levels compared to the overall norm for college students. Contrary to the literature, anxiety did not increase in the study population over time spent in the program, rather students beginning clinical nursing courses (midway through the program of study) experienced the most alarming levels of state and trait anxiety. In order to recruit and retain healthy nurses essential to the future of the profession; nurse educators, administrators, and policy makers must become aware of the factors contributing to and the implications of anxiety in student and novice nurses. Anxiety reduction strategies should be implemented at every level to maintain positive learning and working environments.
\end{abstract}

Key Words: Nursing, Anxiety, Education, Newly licensed registered nurse, Anxiety reduction strategies

\section{INTRODUCTION}

Many nurses agree nursing school and the transition to professional practice was one of their most challenging, often frustrating, and perhaps disillusioning life experiences. The rigors of progressing through intense academic and clinical programs, additional work and home obligations, and entering into a field of professional practice that continually evolves may invoke significant life changes leading to feelings of distress and anxiety. Concurrently, hospitals are charged with providing technologically advanced, high quality patient care while hiring and retaining a competent nursing workforce. Meanwhile nursing education is at a crossroads, where programs are turning away thousands of qualified candidates, yet a nursing shortage persists. ${ }^{[1]}$ In order to ensure the future of the profession, nurse educators, staff development nurses, administrators, and policy makers must become aware of and respond to mental health issues associated with nursing education that may affect the transition of students and newly licensed registered nurses (NLRNs) to professional practitioners.

Student nurses are a vital workplace resource, however those in professional development, education, and administration are not aware or do not acknowledge that anxiety among nursing majors is higher than that of the overall collegiate population $^{[2-4]}$ or that the anxiety experienced in nursing

*Correspondence: Monika Wedgeworth; Email: mwedgeworth@ua.edu; Address: The University of Alabama, Tuscaloosa, United States. 
school may continue through role transition into professional practice. ${ }^{[5]}$ Nursing majors also have higher levels of anxiety and higher levels of physiological and psychological symptoms than students in other health related disciplines ${ }^{[2]}$ including medicine, pharmacy, and social work. Competition for entrance into nursing schools, rigorous courses, frequent exams, hours of challenging experiences, working with critically ill persons, and lack of support from faculty and more experienced nurses are a few of the unique stressors reported by students and new graduates. ${ }^{[4,6]}$ This excessive anxiety may lead to poor role transition, burnout, poor job performance, or novice nurses leaving the profession all together. ${ }^{[5,7-9]}$ Of particular concern to nurse educators and those who train or work with NLRNs, research has consistently found that the greatest source of anxiety in students are the clinical experiences and client interactions that are unique to nursing education. In today's complex care settings, it is imperative that nurse educators go beyond simply teaching content and facilitate learning environments that nurture and build resilience in future practitioners. To accomplish this, nurse educators and nurse managers must become aware of the time in the program of study high levels of anxiety are occurring in students.

Retaining nurses is critical as the work forces ages towards retirement and healthcare resources become increasingly limited. Nurses report they are faced daily with emotionally and physically demanding work. ${ }^{[10]}$ NLRNs are often expected to "hit the ground running", and research suggests that younger nurses experience the most distress in the practice setting ${ }^{[11]}$ and the transition to professional practice is described as challenging, confusing, and sometimes shocking. ${ }^{[5]}$ Not surprisingly, $91 \%$ of new graduate nurses report their job is stressful. ${ }^{[12]}$ In registered nurses age 24 and younger, psychological distress (anxiety, depression, irritability) is higher than that of healthcare providers of all ages and is a significant factor contributing to turnover and attrition. ${ }^{[12]}$ Negative feelings are attributed to work overload, unsupportive practice settings, ${ }^{[7]}$ inadequate role preparation, and feeling overwhelmed or frustrated. ${ }^{[5]}$

A student nurse's first years of professional experience often lays the foundation for what will hopefully be long-term professional satisfaction. While transition to professional practice can be exciting and challenging, it can also be a time of high anxiety; especially when the realities of work do not meet existing expectations and feelings of fatigue or isolation have set in. Duchscher ${ }^{[5]}$ has conducted extensive research surrounding role and transition shock in nursing, describing it as the person "jumped into the deep end of the pool" while not being prepared for the reality of the transition's effects on their personal and professional self-concepts.
Feelings of shock at new-found and unexpected realities can have negative implications on aspects of physical well-being, emotions, social development, and intellectual capabilities.

\section{Review of literature}

The review of literature demonstrates the alarmingly high prevalence of moderate to severe anxiety in both college students overall and particularly in nursing students. As many as $23.4 \%$ of college students report that their anxiety has been high enough to affect their academic performance within the last 12 months, ${ }^{[13]}$ and studies show that anxiety among nursing majors is higher than that of the overall collegiate population. ${ }^{[2-4]}$ A mixed method study of baccalaureate nursing students in traditional and second degree programs found that nursing students are experiencing very high levels of stress. ${ }^{[14]}$ The researchers found that in their study sample, $95 \%$ of students reported feeling anxiety in stressful situations, $87.8 \%$ ranked worry extremely high, and $42.1 \%$ reported feelings of depression when under stress. The presence of excessive anxiety can negatively impact college students' and nursing students' cognitive abilities, physical health, and overall ability to effectively and safely provide care to patients. ${ }^{[6,15-17]}$ Goff $^{[18]}$ found that baccalaureate nursing students experiencing high levels of both personal and academic stressors reported that deadlines, an overload of things to accomplish, competition for grades, test anxiety, procrastination, and perfectionism caused significant stress. The nursing students reported that their most frequent emotional reactions were fear, anxiety, and worry, behavioral responses were reported as crying and irritability, and their psychological responses were exhaustion and sweating. Chernomas and Shapiro ${ }^{[19]}$ also noted that the multiple demands of nursing school created significant stress in students, leading to insufficient sleep and nutrition as well as negative impacts on learning and safe clinical practice. The literature also indicates that anxiety levels increase as students' progress through nursing programs, with the highest levels of anxiety existing in the most experienced students. ${ }^{[8,20,21]}$ While all students report high levels of distress, first year students report more distress related to academics and second year students report the most distress related to clinical experiences. ${ }^{[22]}$

Clinical practice is a significant portion of nursing education, requiring students to spend considerable amounts of time away from campus, friends, and family. Nursing students, no matter their year of study, perceive clinical stressors have an impact on their psychological well-being ${ }^{[23]}$ with role strain and inadequate classroom preparation for clinical encounters cited as main student stressors. ${ }^{[24]}$ As care has moved to the community, patients remaining in hospitals re- 
quire more intensive and technologically advanced services; placing additional stressors on students learning in clinical environments. They are expected to apply didactic content and utilize efficient critical thinking skills in continually complex, technologically advanced, evolving healthcare environment. ${ }^{[3,4,24]}$ Clinical anxiety is often related to the behaviors of the faculty, staff nurses, and physicians on the units as well as fear of making mistakes and performance of skills. ${ }^{[16,26]}$ Significant to nurse educators at every level of professional development, high levels of clinical anxiety have been noted to negatively affect the students' skills in performing a new procedure $^{[15]}$ as well as increase the possibility of negative patient outcomes. ${ }^{[27]}$ Melo and colleagues ${ }^{[6]}$ reported that students experienced high levels of anxiety during clinical practice to the point of interfering with learning and negatively impacting mental health. While some may consider the stress and associated anxieties of nursing school a "rite of passage", the consequences of these so called "rites" can have far reaching detrimental consequences.

In current healthcare environments, students are faced with increasingly complex patient care, which is often laden with high workload demands. ${ }^{[5,28]}$ Studies reveal that high levels of anxiety continue even after nursing students have graduated school and begun the transition into practice, with up to $66 \%$ of new nurse graduates experiencing severe levels of burnout and emotional exhaustion. ${ }^{[29]}$ Numerous studies have indicated that high levels of anxiety can have negative impacts on how students are able to perform on the clinical unit, ${ }^{[6,15-17,30]}$ and this reality may lead to burnout which may persist post-graduation. ${ }^{[5-9]}$ Burnout describes a psychological syndrome (exhaustion, cynicism, and ineffectiveness) experienced when a person is exposed to repeated workplace stressors, ${ }^{[31]}$ and academic and clinical pressures may cause burnout symptoms as early as nursing school. ${ }^{[8]}$ Burnout not only predicts poor health but also reduces mastery of nursing skills and decreases the use of evidence-based practice up to one year post graduation. ${ }^{[32]}$ In a 2006 study, 66\% of NLRNs reported experiencing severe burnout. ${ }^{[29]}$ Researched factors contributing to nurses' experiences of burnout are work overload, high patient to nurse ratios, time constraints, and lack of professional support from more experienced nurses and administrators, workplace incivility, and a reduced sense of autonomy. ${ }^{[7,31,32]}$

Factors associated with recruitment and retention of a stable and healthy nursing workforce emphasize that turnover and attrition are continual concerns for both schools and healthcare organizations. The global demand for nurses is increasing as populations' age and healthcare legislation changes. Student and NLRN turnover and attrition have significant detrimental financial, staffing, and patient care effects for all

Published by Sciedu Press stakeholders involved in the training and staffing of nurses. Student attrition rates from baccalaureate nursing programs may be as high as $50 \% \cdot{ }^{[33]}$ Studies of the first job experiences of NLRNs turnover rates are as high as $30 \%$ leaving in the first year and 57\% leaving in the second year. ${ }^{[12]}$ The cost of one RN leaving their position can be as high as $\$ 82,000 .^{[34]}$ Given the association and consequences of emotional exhaustion, anxiety, and turnover or attrition; it is critical that all involved in the training of student and NLRNs investigate and mitigate sources of stress and anxiety when possible.

Anxiety is a common emotional state that can be either motivating or debilitating. ${ }^{[35]}$ This study examined the nursing students' state and trait anxiety. State anxiety is the unpleasant emotion that results from the current experience of anxiety, defined as "an emotional reaction that consists of subjective feelings of tension, apprehension, nervousness, and worry" ${ }^{[36]}$ Trait anxiety is the description of the differences in individuals' anxiety as a personality trait, defined as "the tendency to see the world as dangerous". ${ }^{[36]}$ Previous studies have shown that nursing students report increasing anxiety over time spent in a nursing program. ${ }^{[3,8,20-23]}$ However there is limited research that examines a cross-section (pre-nursing, early nursing, and late nursing students) of baccalaureate nursing student cohorts' anxiety at specific points in the program of study. This study sought to answer two research questions: (1) Is there a difference between prenursing, early nursing, and late nursing student state anxiety among baccalaureate nursing students and (2) Is there a difference between pre-nursing, early nursing, and late nursing student trait anxiety among baccalaureate nursing students. The researcher hypothesized, based upon existing literature, that nursing student anxiety would increase over time spent in a nursing program, with late nursing students having the highest levels of both state and trait anxiety.

\section{METHODS}

The study design was descriptive and cross-sectional, involving undergraduate baccalaureate nursing students from a single public university located in the south. Basic demographic data was collected including level in the program, age, gender, and race. State and trait anxiety data was collected via the State-Trait Anxiety Inventory (STAI), an instrument that quantifies adult anxiety. This study examined three points of state and trait anxiety among baccalaureate nursing students, in addition to the aforementioned research questions, students were also asked to rank the main source of their anxiety (academic, clinical, or personal). The data collection instrument was converted to upload to the online survey with permission from Mindgarden.com. The STAI was chosen because it has been utilized extensively in research and clinical 
practice. It was originally developed to be used with high school students, college students, and adults, which matched the anticipated age groups of the participants. ${ }^{[37]}$

Before the study began, university Institutional Review Board (IRB), or ethics board approval was obtained. Following IRB approval, the researcher identified courses and instructors at the university in which the pre-nursing, early nursing, and late nursing students were enrolled. The researcher sent an email message to the instructors of the identified courses for the potential participants notifying them of the purpose of the study, contact information, and a request to meet with students either before or after a scheduled class period. None of the identified courses included courses in which the researcher was currently teaching. Over a period of two weeks the researcher visited the classrooms in the identified courses at the time that was deemed as most appropriate to the instructor of the course. The researcher discussed the research study verbally based upon the script approved by the institution's IRB. Potential participants were provided a hard copy of the consent form which contained a link to the anonymous online survey. The online survey contained an additional question related to informed consent to participate in the study. The decision to use the web-based questionnaire format was based upon convenience and that there was little interruption to classroom time for participants. Students were able to complete the survey in a location and time of their choosing. The research participants completed the online survey at their convenience over a time period of two weeks from initial contact with the researcher. The majority of the research participants completed the survey within 48 hours of receiving the consent form. Confidentiality was maintained as the researcher had no knowledge that students participated in the survey and had no contact with the participants following the initial study recruitment period. Anonymity was ensured as no identifying information, including IP address, was collected during the survey process. The data was collected utilizing the online survey system and entered into a statistical analysis package.

\subsection{Sample}

The demographic data of the sample, which were generally female $(92.4 \%)$, white (95\%), and ages $19-22$ (84\%). The sample was conceptually divided into three cohort groups. Pre-nursing students at the freshman and sophomore years, were completing coursework that is heavily focused on the sciences, math, and liberal arts. They also faced the pressures of grade competition for entry into the upper levels of the nursing program. Early nursing students at the junior year had been admitted to the upper levels of the nursing program and were completing courses that are heavily sci- ence based. They are beginning clinical courses that have intensive content demands and clinical based lab and hospital time requirements. Late nursing students, seniors, had completed many of their clinical courses and were preparing to complete the program exit examination, the national board examination for licensure, as well as preparation for future professional employment.

\subsection{Sample size, power, and precision}

Sample size calculated prior to study implementation utilizing SPSS Sample Power 3.0 found that 30 participants per group (pre-nursing, early nursing, and late nursing) yielded a power of .96 with a large effect size, .40. 43 of 198 distributed surveys were completed by pre-nursing students (21.7\%), 43 of 90 by early nursing students $(47.7 \%)$, and 33 of 86 by late nursing students $(38.3 \%)$ resulting in 119 study participants. ( $\mathrm{N}=43$ pre-nursing, 43 early nursing, and 33 late nursing students). According to Spielberger and colleagues, ${ }^{[37]}$ the $S D$ for S-Anxiety is $10.02-11.95$ and TAnxiety 9.18-10.15 (males to females).

The STAI contains two 20-item self-report subscales for measuring state and trait anxiety, developed to be used with high school students, college students, and adults. ${ }^{[37]}$ The S-Anxiety subscale (Form Y-1) measures how participants feel "right now". The T-Anxiety subscale (Form Y-2) assesses how the participant "generally feels". Each item on the STAI utilizes a weighted score ranging from 1 to 4 . Both the state and trait anxiety scales had a high levels of internal consistency, as determined by Cronbach's alphas of 0.956 (state) and 0.932 (trait). The Form Y S-Anxiety coefficients ranged from .91-.93 and T-anxiety coefficients ranged from .88 to .92 . The test-retest coefficients ranged from .16 to .62 for S-Anxiety and .73-.86 for T-Anxiety. Alpha reliability coefficients for large samples of college students for the Form-Y S-Anxiety and T-Anxiety scales were .86 and .90 , when computed by KR-20 as modified by Cronbach. ${ }^{[37]}$ The correlations between S-Anxiety and T-Anxiety scales are $.59-.75 .^{[37]}$

\section{RESUlts}

The demographic data and level in the nursing program was coded within the statistical analysis package. The STAI results were scored and totaled and entered into the statistical analysis package for evaluation. The mean scores and standard deviation for each group were calculated. The data were then evaluated within the statistical analysis package utilizing multivariate analysis of variance (MANOVA). Levene's test of equality of error variances and Tukey post-hoc analysis were also performed. Reliability statistics were performed and evaluated for all items on the STAI. The ad- 
ditional questions of ranking anxiety by group and source were cross-tabulated and downloaded utilizing the existing online survey software.

The mean for all participants of the S-Anxiety subscale was $46.6162(S D=13.94509)$. The mean scores for the S-Anxiety subscale for prenursing students was 49.5854 ( $S D$ $=12.80230)$, for early nursing students was 51.1667 ( $S D=$ 14.05723), and for late nursing students was 37.1212 ( $S D=$ 10.45753). The mean for all participants of the T-Anxiety subscale was $44.0517(S D=11.40926)$. The mean scores for the T-Anxiety subscale for prenursing students was 45.8293 $(S D=10.18308)$, for early nursing students was 48.8095 ( $S D$ $=11.03705)$, and for late nursing students was 35.7879 (SD $=8.82736$ ).

For the variable of state anxiety, $F=1.408(2,113), p=$ .207. There is not a significant variance difference between the study groups' state anxiety. For the variable of trait anxiety, $F=1.173(2,113), p=.303$. There is not a significant variance difference between the study groups' trait anxiety. There was homogeneity of variances as determined by Levene's Test of Homogeneity of Variance $(p>.05)$.

A MANOVA was conducted to evaluate between subject effects (see Table 1-STAI Tests of Between Subjects). There was a statistically significant difference between the prenursing, early nursing, and late nursing state anxiety levels, $F=13.089(2,113), p=.000$; as well as a statistically significant difference between the pre-nursing, early nursing, and late nursing trait anxiety levels, $F=16.188(2,113), p=$ .000 (see Table 1-STAI Tests Between Subjects).

Table 1. STAI Tests of Between Subjects

\begin{tabular}{lllllll}
\hline \multirow{2}{*}{ Source } & $\begin{array}{l}\text { Dependent } \\
\text { Variable }\end{array}$ & $\begin{array}{l}\text { Type III } \\
\text { Sum of } \\
\text { Squares }\end{array}$ & df & $\begin{array}{l}\text { Mean } \\
\text { Square }\end{array}$ & $\boldsymbol{F}$ & Sig \\
\hline Group & State total & $4,206.243$ & 2 & $2,103.122$ & 13.089 & .000 \\
& Trait total & $3,333.893$ & 2 & $1,666.947$ & 16.188 & .000 \\
\multirow{2}{*}{ Error } & State total & $18,157.300$ & 113 & 160.684 & & \\
& Trait total & $11,635.796$ & 113 & 102.972 & & \\
& State total & $274,395.000$ & 116 & & & \\
& Trait total & $240,074.000$ & 116 & & & \\
\hline
\end{tabular}

Tukey post-hoc analysis was conducted to determine the effect of group (pre-nursing, early nursing, and late nursing) on state and trait anxiety levels. The grouping of students were pre-nursing (group 1), early nursing (group 2), and late nursing (group 3). State anxiety levels between the groups are shown in Table 2 Post-Hoc Multiple Comparisons State Anxiety. Tukey post-hoc tests showed that for state anxiety scores, students in the late nursing group (group 3, mean = 37.1212) had statistically significantly lower mean state anxi-

Published by Sciedu Press ety scores than the students from either pre-nursing (group 1, mean $=49.5854, p<.0005$ ) or early nursing (group 2 , mean $=51.1667, p<.0005$ ), but not between pre-nursing (group 1 , mean $=49.5854, p=.837$ ) and early nursing (group 2, mean $=51.1667, p=.837)$.

Table 2. Post-Hoc Multiple Comparisons State Anxiety

\begin{tabular}{llllll}
\hline $\begin{array}{l}\text { Dependent } \\
\text { Variable }\end{array}$ & (I) Group & (J) Group & $\begin{array}{l}\text { Mean } \\
\text { Difference }\end{array}$ & $\begin{array}{l}\text { Std. } \\
\text { Error }\end{array}$ & Sig \\
\hline State Total & 1.00 & 2.00 & -1.5813 & 2.78297 & .837 \\
& & 3.00 & 12.4642 & 2.96451 & .000 \\
State Total & 2.00 & 1.00 & 1.5813 & 2.78297 & .837 \\
& & 3.00 & 14.0455 & 2.94873 & .000 \\
State Total & \multirow{2}{*}{3.00} & 1.00 & -12.4642 & 2.96451 & .000 \\
& & 2.00 & -14.0455 & 2.94873 & .000 \\
\hline
\end{tabular}

Trait anxiety levels between the groups are shown in Table 3 Post-Hoc Multiple Comparisons Trait Anxiety. Tukey posthoc tests demonstrated for trait anxiety scores, students in the late nursing group (group 3, mean $=45.8293$ ) had statistically significantly lower mean trait anxiety scores compared to the students from either pre-nursing (group 1, mean $=48.8095, p<.0005$ ) or early nursing (group 2 , mean $=$ $48.8095, p<.0005$ ), but not between pre-nursing (group 1 , mean $=45.8293, p=.377$ ) and early nursing (group 2, mean $=48.8095, p=.377)$

Table 3. Post-Hoc Multiple Comparisons Trait Anxiety

\begin{tabular}{llllll}
\hline $\begin{array}{l}\text { Dependent } \\
\text { Variable }\end{array}$ & (I) Group & (J) Group & $\begin{array}{l}\text { Mean } \\
\text { Difference }\end{array}$ & $\begin{array}{l}\text { Std. } \\
\text { Error }\end{array}$ & Sig \\
\hline State Total & \multirow{2}{*}{1.00} & 2.00 & -2.9803 & 2.22783 & .377 \\
& & 3.00 & 10.0414 & 2.37315 & .000 \\
State Total & \multirow{2}{*}{2.00} & 1.00 & 2.9803 & 2.22783 & .377 \\
& & 3.00 & 13.0216 & 2.36052 & .000 \\
State Total & \multirow{2}{*}{3.00} & 1.00 & -10.0414 & 2.37315 & .000 \\
& & 2.00 & -13.0216 & 2.36052 & .000 \\
\hline
\end{tabular}

The STAI form Y-1 measured students' state anxiety and consisted of 20 questions. The scale had a high level of internal consistency, as determined by a Cronbach's alpha of 0.956. Similarly, the STAI form Y-1 measured students' trait anxiety and consisted of 20 questions. The scale had a high level of internal consistency, as determined by a Cronbach's alpha of 0.932 .

\subsection{Results compared to normed population}

The results of this study were also compared to the STAI normed population scores. The recommendation of the scoring guide is not to label one respondent or group as "anxious" or "not anxious", but rather to compare the raw state or trait anxiety score to that of the norm table within the STAI 
scoring manual. ${ }^{[37]}$ The higher the raw state or trait anxiety score indicates higher state and trait anxiety. For example, among pre-nursing students, the mean state anxiety score in this study was 49.5854 and the mean trait anxiety score was 45.8293 .

Utilizing the STAI scoring manual, ${ }^{[37]}$ the state anxiety score for pre-nursing students is $59 \%$ (see Table 4 ). $41 \%$ of college students scored higher than the pre-nursing students' state anxiety and $59 \%$ of college students scored lower than the pre-nursing students' state anxiety. Early nursing students scored above the normed population of college students as well, $60 \%$ for state anxiety and $58 \%$ for trait anxiety. The late nursing students scored slightly below average as compared to the normed population of college students, $49 \%$ for state anxiety and $46 \%$ for trait anxiety. In summary, the STAI state and trait anxiety scores of the pre-nursing and early nursing groups were well above the normed population for college students (see Table 4-Nursing Students' STAI Scores Compared to STAI Norm for College Students).

Table 4. Nursing Students' STAI Scores Compared to STAI Norm for College Students

\begin{tabular}{lll}
\hline Group & Mean & STAI Norm \\
\hline (1) Pre-nursing-State & 49.5854 & 59 \\
(1) Pre-nursing-Trait & 45.8293 & 56 \\
(2) Early nursing-State & 51.1667 & 60 \\
(2) Early nursing-Trait & 48.8095 & 58 \\
(3) Late nursing-State & 37.1212 & 49 \\
(3) Late nursing-Trait & 35.7879 & 46 \\
All Groups-State & 46.6121 & 57 \\
All Groups-Trait & 44.0517 & 54 \\
\hline
\end{tabular}

\subsection{STAI responses}

A review of the responses within the data collection instrument distributed by group, showed that the pre-nursing and early nursing students exhibited the most state anxiety. The anxiety absent question, "I feel calm" identified that $63 \%$ of pre-nursing and $60 \%$ of early nursing students selected "not at all" or "somewhat" as compared to only $12 \%$ of late nursing students who selected that option. Similar results were identified for responses to other anxiety absent questions such as "I feel comfortable" (59\%, 62\%, 24\%) and "I am relaxed" $(83 \%, 66 \%, 36 \%)$. Anxiety present state anxiety questions identified the same pattern of responses. The question, "I am presently worrying over possible misfortunes" showed that $59 \%$ of pre-nursing and $57 \%$ of early nursing selected "moderately so" or "very much so" as compared to $21 \%$ of late nursing students. Similar responses were identified for other anxiety present questions such as "I feel nervous" $(68 \%, 55 \%, 27 \%)$ and "I am worried" (68\%, 57\%, $24 \%)$.

A review of the responses within the data collection instrument, distributed by group, and showed that the pre-nursing and early nursing students exhibited the most trait anxiety. The anxiety absent question, "I feel rested" identified that $61 \%$ of pre-nursing students and $90 \%$ of early nursing students selected "almost never" or "sometimes" as compared to $45 \%$ of late nursing students. Similar results were identified for responses to other anxiety absent questions such as "I make decisions easily" (56\%, 69\%, 18\%) and "I am calm, cool, and collected" $(61 \%, 71 \%, 21 \%)$. Anxiety present trait anxiety questions identified the same pattern of responses. The question, "I worry too much over something that really doesn't matter" showed that $61 \%$ of pre-nursing and $71 \%$ of early nursing students selected "often" and "almost always" as compared to $21 \%$ of late nursing students. Similar results were identified for responses to other anxiety present questions such as "I get in a state of turmoil as I think of my recent concerns and interests" $(54 \%, 50 \%, 15 \%)$ and "I feel difficulties are piling up so that I cannot overcome them" $(42 \%, 43 \%, 10 \%)$.

\subsection{Ranking of anxiety source}

Pre-nursing, early nursing, and late nursing students were asked to rate their anxiety at the end of the survey by source, academic, clinical, and personal. A ranking of 1 indicated the highest source of anxiety, a ranking of 2 indicated the second highest source of anxiety, and a ranking of 3 indicated the lowest source of anxiety of the three choices provided. For the ranking portion of the survey, thirty-five pre-nursing students, thirty one early nursing students, and thirty late nursing students completed the ranking. Pre-nursing students ranked academics as the main source of anxiety at a rate of $30 / 35$ or $86 \%$. Early nursing students ranked academics as the main source of anxiety at a rate of $26 / 31$ or $84 \%$. Late nursing students ranked academics as the main source of anxiety at a lower rate of $19 / 30$ or $63 \%$.

\section{DiscuSSION}

This study contributes unique knowledge related to the timing of anxiety within a baccalaureate program of study and revealed high levels of anxiety as compared to college student normed populations. Two of the study groups, the pre-nursing and early nursing groups, were experiencing anxiety at levels significantly higher than the normed population of college students for the STAI (see Table 4). In studies conducted by Deary and colleagues, ${ }^{[20]}$ Rella and colleagues, ${ }^{[8]}$ and Timmins and colleages, ${ }^{[21]}$ nursing students' stress and anxiety were all increased over time spent 
in the nursing program and were highest in the final year of study. Unlike the findings established in the majority of the literature and the study hypothesis, late nursing students in this study had the lowest levels of both state and trait anxiety as compared to the pre-nursing and early nursing students, while the pre-nursing and early nursing sample groups had the highest levels of both state and trait anxiety and experienced anxiety higher than the established norm. This was further demonstrated within examples given of the STAI responses, with $90 \%$ of early nursing students stating that they "almost never" or "sometimes" feel rested and 71\% stating that they "almost never" or "sometimes" feel calm cool, and collected. Possible causation is that pre-nursing students are completing the coursework for entrance into the nursing program and are faced with the stressors of intense grade competition for upper level nursing program promotion. Early nursing students have been promoted into the nursing program and are enrolled in the intensive fundamentals and pharmacology courses. They are also tasked with making the transition from classroom teaching to intensive practice lab and hospital clinical time. Failure to succeed at this point in the program of study can drastically alter future career plans, causing students to either change their major or select another institution in which to pursue nursing study. The late nursing students may have had the benefit of experience and time to adjust to the rigors of nursing school, as well has have established effective anxiety coping mechanisms. All students in this study ranked academics as their highest source of anxiety as compared to clinical or personal anxiety producing stimuli. Possible causation is that this school of nursing requires a competitive grade point average for admission to the nursing courses, and nursing course and curriculum exit examinations, possibly ranking academic anxiety in these nursing students higher than other sources.

\subsection{Limitations}

There were identified limitations that may have affected validity associated with this study. First, selection bias; the study participants were selected through a convenience sample of baccalaureate nursing students from three pre-determined points in a single nursing program. Therefore, the findings may not be consistent with other college students from private institutions and/or from colleges outside of the south. The participants may have personal reasons not disclosed for choosing to participate in this study. The timing of data collection may have affected the validity of the results as the researcher was unaware of upcoming exams or clinical placements at the time of data collection. This school of nursing does have competitive entrance grade point average admission criteria to the nursing program during the sophomore

Published by Sciedu Press year, as well as course and curriculum exit examinations for the nursing courses. These limitations alone could possibly raise anxiety in this group of nursing students. Data was not collected related to students repeating courses, changing majors, or students out of sequence in courses, which could be a contributing factor to anxiety. Another identified threat to the validity of this study is the lack of diversity within the study sample. The study participants were mainly white $(95 \%)$ female $(92.4 \%)$ students primarily aged 19-22 (84\%). The STAI is a self-report assessment of anxiety that was completed in a setting convenient to the student. The data obtained from the survey may have been affected by transitory anxiety producing situations or stressful environments. Spielberger and colleagues ${ }^{[37]}$ suggested that subjects take the survey in controlled and similar environments. To address this limitation, the instructions provided in the IRB approved recruitment script suggested the student complete the survey in a secure and comfortable location.

\subsection{Implications for nursing education}

Despite identified limitations, the results of this study demonstrate that state and trait anxiety among two of the sample groups of baccalaureate nursing students was significantly and alarmingly higher than the normed population of college students. The identification of the points in a program where high levels of anxiety is occurring may allow faculty to evaluate possible curriculum based sources and/or develop interventions to assist students to decrease anxiety. Classroom, clinical, and workplace settings are critical learning environments for both students and NLRNs, and as healthcare environments become increasingly complex they also become increasingly stressful, with the potential to produce negative anxiety effects. Faculty and hospital administrators working closely with students at all academic levels should be encouraged to remain vigilant to outward signs of student anxiety and periodically debrief students by discussing anxiety in a non-threatening manner. Staff development educators and administrators must also observe and monitor the effect of anxiety on the performance and patient care outcomes of the nurses they supervise. Thankfully, there are several well-researched and highly effective intervention strategies that have been shown to decrease anxiety in both students and NLRNs.

Many anxiety reduction strategies are available that are simple and cost effective to implement. Students' social perceptions of their faculty, co-workers, and administrators have been shown to have a large and direct effect on anxiety, burnout, and turnover intention. Faculty who are friendly, inviting, and use humor as teaching strategy elicit less anxiety in their students. ${ }^{[26,30]}$ These strategies are also important 
tools for nurse managers and staff nurses as student and NLRNs' feelings of negativity (such as incivility) have a direct impact on their mental health. ${ }^{[31]}$ Peer instructors and mentors are another cost effective anxiety reduction strategy that can be implemented in healthcare settings. Mentoring reinforces learning while promoting trusting relationships and collegiality among students or NLRNs when they are paired with more experienced faculty or staff nurses. ${ }^{[26]}$ Considering that lack of support or guidance is a significant reason that NLRNs leave their first job, mentoring programs in hospital environments can be critical to the reduction of turnover. ${ }^{[12]}$ Led by professional development, team building exercises and open forums for communication can also help student nurses, NLRNs, and experienced nurses on the unit establish a culture of collaboration and collegiality. Another research topic that has gained recent popularity is the use of mindfulness training to reduce anxiety. Mindfulness programs have been shown to be highly effective and range from yoga to meditation and body scans. ${ }^{[26]}$ Mindfulness activities can vary in length and may include workshops, seminars, or even a course elective.

Research has summarily found that inadequate training has a direct effect on the novice nurse's ability to remain in the profession, ${ }^{[38]}$ and the resulting lack of confidence combined with the demands of clinical practice may lead to psychological distress. ${ }^{[39]}$ Of concern to educators at all levels, NLRNs state that their education prepared them more for National Council of State Boards of Nursing (NCLEX) than the demands of clinical practice. ${ }^{[12]}$ Role preparation programs that focus on increasing confidence and reducing anxiety by training students and NLRNs communication skills, time management, technical skills, conflict resolution, and stress reduction techniques are often most successfully implemented through nurse residency programs. Ideally residency programs should be encouraged by nursing faculty and used as hiring incentives by human resource staff to recruit students prior to graduation from nursing school. Residency programs typically combine classroom lecture or seminars with the use of an experienced clinical mentor and last between six months to one year. Residency programs can increase NLRN retention as high as $95.6 \%{ }^{[40]}$ and decrease the transition shock associated with the nurse's new role. ${ }^{[5]}$ At the minimum, faculty and hospital administrators should ensure that pre-licensure courses and nurse orientation programs include preparation for the demands of professional nursing and basic stress management techniques.

Not knowing a skill or how to respond to a situation is often cited as a reason for anxiety in student and NLRNs; $[25,41]$ and simulation has been shown to reduce anxiety prior to clinical experiences. ${ }^{[42]}$ Simulation can encompass a wide variety of forms, from cost effective simple role playing scenarios and standardized patients to the use of expensive high fidelity mannequins. A myriad of research exists demonstrating the effectiveness of various types of simulation in nursing programs. Nursing skills that target anxiety reduction and enhance confidence, such as communication, conflict resolution, technical skills, and critical thinking, can all be accomplished via simulation. For example, a simple role playing scenario related to an issue that has caused a nurse to become anxious or upset in the clinical setting allows for the sharing of feelings as well as the acclimation of new skills to aid the nurse in the future. The use of standardized patients has been shown to reduce the clinical anxiety related to interacting with mental health patients. ${ }^{[43]}$ Ideally simulation scenarios are multidisciplinary, enhance team building, collegiality, and encourage open communication between all members of the healthcare team.

\section{Conclusion}

The results of this study demonstrate the need for nursing programs to evaluate programs of study for high risk anxiety points, investigate how anxiety might be negatively impacting student success, and develop strategies to mediate anxiety in students. The students in this study, particularly the early nursing students, were experiencing state and trait anxiety at levels well above the normed population of college students and significantly higher than the two other sample groups. The literature demonstrated that high levels of anxiety in nursing students has detrimental effects on the students' mental and physical well-being, economic impacts for both schools and hospitals, and produce poor academic and clinical performance program outcomes. Future research relating anxiety to outcomes such as measurements of physical well-being, coping mechanisms, course grades, or clinical evaluations could provide further insight into the effects of anxiety on nursing students. Additionally, longitudinal research should be conducted to focus on both the levels and sources of anxiety experienced by one group and how they change during progression throughout the program of study and role transition into professional practice.

Nurses at all levels value supportive, positive work environments that uphold the standards of the profession while allowing them to provide high quality patient care. It is the responsibility of nurse educators and administrators to address the anxiety related to nursing education to retain the workforce vital to the future of the profession. Collaboration between schools of nursing and healthcare administrators is essential to address and identify measures that will adequately prepare student and NLRNs for their professional career. Decreasing nursing student anxiety is key to address- 
ing current and future nursing shortages, as more students will complete their education and have successful transitions to practice. As anxiety is decreased, learning in classroom, clinical, and workplace settings is increased. It is critical that educators and administrators at all levels of nurse development be vigilant in creating and maintaining positive learning and working environments, as this has been repeatedly proven to reduce anxiety and resulting transition shock, burnout, turnover, and attrition in student and novice nurses.

\section{CONFlicts of InTEREST Disclosure}

The authors declare that there is no conflict of interest.

\section{REFERENCES}

[1] American Association of Colleges of Nursing. Nursing shortage fact sheet. Retrieved July 1, 2012. Available from: http://www.aacn.nche.edu/media-relations/fact-she ets/nursing-shortage

[2] Beck D, Srivastava R, Rockwell B. Perceived level and sources of stress in university professional schools. Journal of Nursing Education. 1997; 36(4): 180-186. PMid:9107596.

[3] Dzurec L, Allchin L, Engler A. First-year nursing students' accounts of reasons for student depression. Journal of Nursing Education. 2007; 46(12): 545-551. PMid:18196838.

[4] Gibbons C, Dempster M, Moutray M. Stress, coping, and satisfaction in nursing students. Journal of Advanced Nursing. 2011; 67(3): 621632. PMid:21077931. 10.1111/j.1365-2648.2010.05495 . x

[5] Duchscher J. Transition shock: The initial stage of role adaptation for newly graduated Registered Nurses. Journal of Advanced Nursing. 2009; 65(5): 1103-1113. PMid:19183235. http://dx.doi.org/1 $0.1111 / j .1365-2648.2008 .04898 . x$

[6] Melo K, Williams B, Ross C. The impact of nursing curricula on clinical practice anxiety. Nurse Education Today. 2010; 30: 773-778. PMid:20381219. http://dx.doi.org/10.1016/j.ned t.2010.02.006

[7] Laschinger HK, Finegan J, Wilk P. New graduate burnout: The impact of professional practice environment, workplace civility, and empowerment. Nursing Economics. 2009; 27(6): 377-383. PMid:20050488.

[8] Rella S, Winwood P, Lushington K. When does nursing burnout begin? An investigation of the fatigue experience of Australian nursing students. Journal of Nursing Management. 2008; 17: 886-897. PMid:19793246. http://dx.doi.org/10.1111/j.1365-2834. 2008.00883. $x$

[9] Unruh LY, Nooney J. Newly licensed registered nurses' perceptions of job difficulties, demands and control: Individual and organizational predictors. Journal of Nursing Management. 2011; 19: 572-584. PMid:21749531. http://dx.doi.org/10.1111/j.1365-2834. 2011.01239.x

[10] Leiter MP, Laschinger HKS. Relationships of work and practice environment to professional burnout: testing a causal model. Nursing research. 2006; 55(2): 137-146. http://dx. doi.org/10.1097/0 0006199-200603000-00009

[11] Leiter MP, Price SL, Spence Laschinger HK. Generational differences in distress, attitudes and incivility among nurses. Journal of Nursing Management. 2010; 18(8): 970-980. PMid:21073569. http://dx.doi.org/10.1111/j.1365-2834.2010.01168.x

[12] Bowles C, Candela L. First job experiences of recent RN graduates: Improving the work environment. Journal of Nursing Administration. 2005; 35(3): 130-137. PMid:15761310.

[13] American College Health Association National College Health Assessment, Publications and Reports. Executive Summary. (Spring 2015). Retrieved April 20, 2016. Available from: http://www . ac ha-ncha.org/docs/NCHA-II_WEB_SPRING_2015_UNDERGRA DUATE_REFERENCE_GROUP_EXECUTIVE_SUMMARY.pdf
[14] Reeve K, Shumaker C, Yearwood E, et al. Perceived stress and social support in undergraduate nursing students' educational experiences. Nurse Education Today. 2013; 30: 419-424. PMid:23246284. http://dx.doi.org/10.1016/j.nedt.2012.11.009

[15] Cheung RY, Au TK. Nursing students' anxiety and clinical performance. Journal of Nursing Education. 2011; 50(5): 286-289. PMid:21323251. http://dx.doi.org/10.3928/01484834-201 10131-08

[16] Melincavage S. Student nurses' experiences of anxiety in the clinical setting. Nurse Education Today. 2011; 31: 785-789. PMid:21641701. http://dx.doi.org/10.1016/j.nedt.2011.05.007

[17] Sharif F, Armitage P. The effect of psychological and educational counseling in reducing anxiety in nursing students. Journal of Psychiatric and Mental Health Nursing. 2004; 11: 386-392. PMid:15255911. $10.1111 / j .13652850 .2003 .00720 . x$

[18] Goff AM. Stressors, academic performance, and learned resourcefulness in baccalaureate nursing students. International Journal of Nursing Education Scholarship. 2011; 8(1): 1-20. http://dx.doi .org/10.2202/1548-923X.2114

[19] Chernomas WM, Shapiro C. Stress, depression, and anxiety among undergraduate nursing students. International Journal of Nursing Education Scholarship. 2013; 10(1). http://dx.doi .org/10.1515 /ijnes-2012-0032

[20] Deary I, Watson R, Hogston R. A longitudinal cohort study of burnout and attrition in nursing students. Journal of Advanced Nursing. 2003; 43(1): 71-81. http://dx.doi.org/10.1046/j.1365-2648.20 $03.02674 . x$

[21] Timmins F, Corroon A, Byrne G, et al. The challenge of contemporary nurse education programmes. Perceived stressors of nursing students: mental health and related lifestyle issues. Journal of Psychiatric and Mental Health Nursing. 2011; 18: 758-766. PMid:21985678. http://dx.doi.org/10.1111/j.1365-2850.2011.01780.x

[22] Tully A. Stress, sources of stress and ways of coping among psychiatric nursing students. Journal of Psychiatric and Mental Health Nursing. 2004; 11: 43-47. http://dx.doi.org/10.1111/j.136 $5-2850.2004 .00682 . x$

[23] Jimenez C, Navia-Osorio PM, Diaz CV. Stress and health in novice and experienced nursing students. Journal of Advanced Nursing. 2010; 66(2): 442-455. PMid:20423427. http://dx.doi.org/10 $1111 / j 13652648.2009 .05183 . x$

[24] Higginson R. Fears, worries and experiences of first-year preregistration nursing students: a qualitative study. Nurse Researcher. 2006; 13(3): 32-49. PMid:16594368. http://dx.doi .org/10.77 48/nr2006.04.13.3.32.c5977

[25] Clark CM, Springer PJ. Nurse residents' first-hand accounts on transition to practice. Nursing Outlook. 2012; 60(4): e2-e8. http: //dx.doi.org/10.1016/j.outlook.2011.08.003

[26] Moscaritolo LM. Interventional strategies to decrease nursing student anxiety in the clinical learning environment. Journal of Nursing Education. 2009; 48(1): 17-23. http://dx.doi .org/10.3928/0 1484834-20090101-08 
[27] Cimiotti JP, Aiken LH, Sloane DM, et al. Nurse staffing, burnout, and health care associated infection. American Journal of Infection Control. 2012; 40(6): 486-490. PMid:22854376. http://dx.doi .org/10.1016/j.ajic.2012.02.029

[28] Reddish MV, Kaplan LJ. When are new graduate nurses competent in the intensive care unit? Critical Care Nursing Quarterly. 2007; 30: 199-205. PMid:17579302. http://dx.doi.org/10.1097/01.CN Q.0000278919.29444.b3

[29] Cho J, Laschinger HS, Wong C. Workplace empowerment, work engagement and organizational commitment of new graduate nurses. Nursing Leadership Academy of Canadian Executive Nurses. 2006; 19(3): 43. http://dx.doi.org/10.12927/cjnl.2006.18368

[30] Cook LJ. Inviting teaching behaviors of clinical faculty and nursing students' anxiety. Journal of Nursing Education. 2005; 44(4): 156-161. PMid:15862048.

[31] Babenko-Mould Y, Laschinger HK. Effects of incivility in clinical practice settings on nursing student burnout. International Journal of Nursing Education Scholarship. 2014; 11(1): 145-154.

[32] Rudman A, Gustavsson JP. Burnout during nursing education predicts lower occupational preparedness and future clinical performance: A longitudinal study. International Journal of Nursing Studies. 2012; 49(8): 988-1001. PMid:22542085. http://dx.doi.org/10.1016 /j.ijnurstu.2012.03.010

[33] Newton SE, Moore G. Use of aptitude to understand bachelor of science in nursing student attrition and readiness for the $\mathrm{Na}$ tional Council Licensure Examination-Registered Nurse. Journal of Professional Nursing. 2009; 25(5): 273-278. PMid:19751931. http://dx.doi.org/10.1016/j.profnurs.2009.01.016

[34] Twibell R, St Pierre J, Johnson D, et al. Tripping over the welcome mat: Why new nurses don't stay and what the evidence says we can do about it. American Nurse Today. 2012; 7(6): 357-365.
[35] Endler NS, Kocovski NL. State and trait anxiety revisited. Journal of Anxiety Disorders. 2001; 15: 231-245. http://dx.doi.org/1 $0.1016 / \mathrm{S} 0887-6185(01) 00060-3$

[36] Spielberger CD. Understanding stress and anxiety. New York: Harper and Row; 1979.

[37] Spielberger CD, Gorusch RL, Lushene R, et al. State-Trait Anxiety Inventory for Adults Manual and Sample (Form Y). Palo Alto, CA: Consulting Psychologists Press; 1983.

[38] Halfer D, Graf E. Graduate nurse perceptions of the work experience. Nursing Economics. 2006; 24(3): 150. PMid:16786830.

[39] Lavoie-Tremblay M, O’Brien-Pallas L, Gélinas C, et al. Addressing the turnover issue among new nurses from a generational viewpoint. Journal of Nursing Management. 2008; 16(6): 724-733. PMid:18808467. http://dx.doi.org/10.1111/j.1365-2934. $2007.00828 . \mathrm{x}$

[40] Welding NM. Creating a nursing residency: Decrease turnover and increase clinical competence. Medsurg Nursing. 2011; 20(1): 37 PMid:21446293.

[41] Najjar RH, Lyman B, Miehl N. Nursing students' experiences with high-fidelity simulation. International Journal of Nursing Education Scholarship. 2015; 12(1).

[42] Kahlaila R. Simulation in nursing education: An evaluation of students' outcomes at their first clinical practice combined with simulations. Nurse Education Today. 2014; 34(2): 252-258. PMid:24060462. http://dx.doi.org/10.1016/j.nedt. 2013 .08 .015

[43] Kameg KM, Szpak JL, Cline TW, et al. Utilization of standardized patients to decrease nursing student anxiety. Clinical Simulation in Nursing. 2014; 10(11): 567-573. http://dx.doi.org/10.1016 /j.ecns.2014.09.006 